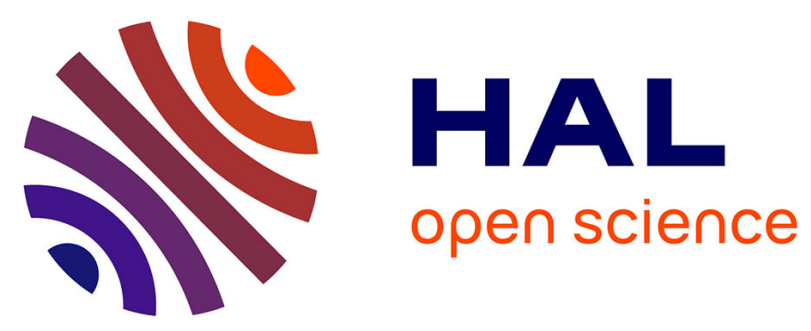

\title{
Experimental characterisation of wave induced flow fields due to an offshore wind farm mast
}

\author{
Isabel García-Hermosa, Jerôme Brossard, Z. Cohen, Gaële Perret, Grégory \\ Pinon, Nizar Abcha, Anne-Claire Bennis, A.B. Ezersky, Dominique Mouazé, \\ Aurélie Rivier Rivier, et al.
}

\section{To cite this version:}

Isabel García-Hermosa, Jerôme Brossard, Z. Cohen, Gaële Perret, Grégory Pinon, et al.. Experimental characterisation of wave induced flow fields due to an offshore wind farm mast. Guedes Soares C. Renewable Energies Offshore, CRC Press, pp.791-797, 2015, 978-1-138-02871-5. 10.1201/b18973-112 . hal-01534081

\section{HAL Id: hal-01534081 \\ https://hal.science/hal-01534081}

Submitted on 6 Jan 2022

HAL is a multi-disciplinary open access archive for the deposit and dissemination of scientific research documents, whether they are published or not. The documents may come from teaching and research institutions in France or abroad, or from public or private research centers.
L'archive ouverte pluridisciplinaire HAL, est destinée au dépôt et à la diffusion de documents scientifiques de niveau recherche, publiés ou non, émanant des établissements d'enseignement et de recherche français ou étrangers, des laboratoires publics ou privés. 


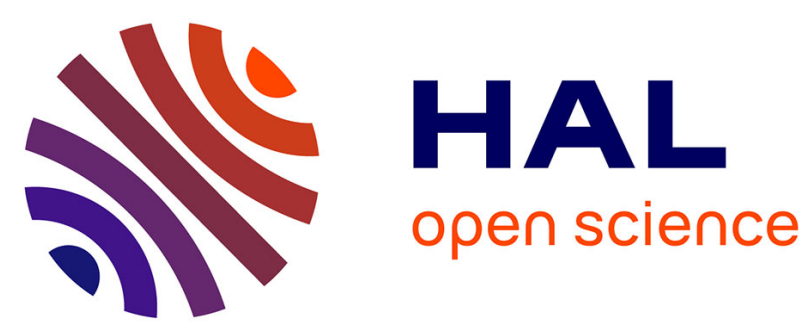

\title{
Experimental characterisation of wave induced flow fields due to an offshore wind farm mast
}

\author{
Isabel García-Hermosa, Jerôme Brossard, Z. Cohen, Gaële Perret, Grégory \\ Pinon, Nizar Abcha, Anne-Claire Bennis, A.B. Ezersky, Dominique Mouazé, \\ Aurélie Rivier, et al.
}

\section{To cite this version:}

Isabel García-Hermosa, Jerôme Brossard, Z. Cohen, Gaële Perret, Grégory Pinon, et al.. Experimental characterisation of wave induced flow fields due to an offshore wind farm mast. Guedes Soares C. Renewable Energies Offshore, CRC Press, pp.791-797, 2015, 978-1-138-02871-5. 10.1201/b18973-112 . hal-01534081

\section{HAL Id: hal-01534081 \\ https://hal.archives-ouvertes.fr/hal-01534081}

Submitted on 6 Jan 2022

HAL is a multi-disciplinary open access archive for the deposit and dissemination of scientific research documents, whether they are published or not. The documents may come from teaching and research institutions in France or abroad, or from public or private research centers.
L'archive ouverte pluridisciplinaire HAL, est destinée au dépôt et à la diffusion de documents scientifiques de niveau recherche, publiés ou non, émanant des établissements d'enseignement et de recherche français ou étrangers, des laboratoires publics ou privés. 


\title{
Experimental characterisation of wave induced flow fields due to an offshore wind farm mast
}

\author{
I. García-Hermosa, J. Brossard, Z. Cohen, G. Perret \& G. Pinon \\ Laboratoire Ondes et Milieux Complexes, Université du Havre, Le Havre, France
}

N. Abcha, A.C. Bennis, A. Ezersky, D. Mouazé \& A. Rivier
Laboratoire Morphodynamique Continentale et Côtière, Caen, France

G. Iglesias, J. Miles, C. Rogan \& D. Simmonds

School of Marine Science and Engineering, Plymouth University, UK

M. Gross \& V. Magar

Centro de Investigación Científica y Educación Superior de Ensenada, Ensenada, Mexico

\begin{abstract}
As part of OFELIA experiments were carried out to characterize the flow field around a cylinder for regular and irregular wave conditions including a 1:10 storm. Data collation included free surface and flow velocity with Acoustic Doppler Velocimeter (ADV) and Particle Image Velocimetry (PIV). Preliminary results identified flow patterns up- and downstream of the cylinder that could play a role on the sediment erosion and deposition patterns near the foundation area, in the short and long term scales.
\end{abstract}

\section{BACKGROUND}

\subsection{Offshore wind farms}

In the last ten years the requirements to generate energy from cleaner sources have pushed the renewable energy industry. Deadlines like the 2020 UK target to achieve the $15 \%$ of the national energy demand from renewable sources (Department of Energy and Climate Change, 2013) resulted in the rapid expansion of the offshore wind energy. The 3rd Round of proposed offshore wind farm sites in the UK were awarded in 2010 and in France the second call for proposals was awarded May 2014 and a third is expected soon.

The French government's goal is 380 MW of installed marine energy capacity by 2020 , or $3 \%$ of France's electricity consumption (Syndicat des Energies Renouvelables, 2014). Moreover, France's offshore wind potential is $90 \mathrm{TWh}$.

These latest proposed developments are being pushed to deeper waters and have increased in scale and technical complexity with ever growing mast diameters and varying foundation options. The choice of mast foundation depends on factors such as: soil characteristics, water depth, hydrodynamic conditions and costs. These factors highlight the need to understand further the local and regional impacts of wind farm foundations.

\subsection{Cylinders and waves}

There have been numerous studies dating from the eighties and nineties investigating the effect of a cylinder on regular wave dynamics such as Dargahi (1989) and Sumer et al (1997). The flow structures developing near the bed due to the presence of a cylinder may be responsible for scour around the structure.

Horseshoe vortices are flow structures associated to scour processes at the upstream end of a cylinder (Sumer et al, 1997, Sumer et al, 2001). According to existing literature (Zanke et al, 2011) the Keulegan Carpenter (KC) number ought to be larger than 6 in order for horseshoe vortices to be present.

$K C=-\frac{U_{m} T}{D}$

where $U_{m}$ is the bottom orbital velocity, $T$ wave period and $D$ the cylinder diameter.

In fact, Sumer et al (1997) observed that typically the horseshoe vortex is suppressed for $K C<6$. They also showed that vortex shedding was present for $K C>4$. More recent studies characterized the different vortex modes on vertical planes along the cylinder (Yang and Rockwell, 2002) and in horizontal planes (Ozgoren et al, 2007 and Lam et al, 2010). Those studies have been conducted for regular waves. 


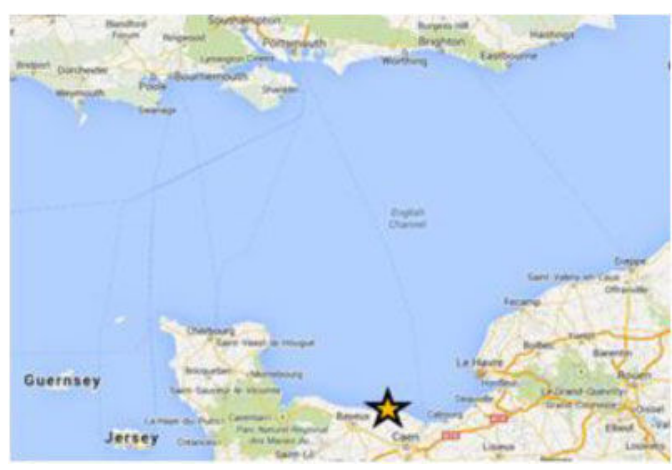

Figure 1. Location of Courseulles-sur-mer in the English Channel (source: Google Maps).

The present investigation aims to widen the knowledge base by providing qualitative and quantitative data in the vicinity of the cylinder to understand the effect of the presence of the cylinder on the bed for irregular waves and a $\mathrm{KC}$ number smaller than 4 .

\subsection{OFELIA - INTERREG project}

The multi partner EU INTERREG funded project OFELIA (http://www.interreg-ofelia.eu/) aims to establish a cross-channel research collaboration to improve the existing understanding of the environmental impacts of offshore wind farm foundations.

Ofelia partners are Universities of Le Havre and Caen Basse-Normandie (France) and Plymouth (UK).

The aims of the project are to be achieved by a combination of experimental laboratory scaled tests and numerical modelling at local and regional scale of the wind farm. A schedule of laboratory tests including a scaled wind farm mast with: waves; waves and currents; and waves, currents and sediment are ongoing in three facilities of the project partners. Numerical modelling is being carried out at Universities of Le Havre and Caen Basse-Normandie.

\subsection{Study area, study site}

An initial desk study was conducted to identify hydrodynamic and sedimentary conditions at the pro-posed French and UK sites in the Channel/Manche area. During the desk study the site of Courseulles-sur-mer, Basse Normandie, France (Figure 1) was chosen as a case study site, a number of frequent and extreme wave conditions were identified for this site.

\subsection{Contents of the paper}

In this paper the experiments carried out at the Laboratoire Ondes et Milieux Complexes (LOMC, U of Le Havre) are discussed. In this facility the testing was done with the presence of wave only forcing and the cylinder.

\section{EXPERIMENTS}

\subsection{Facility and tests rig}

The flume site in the LOMC is $35 \mathrm{~m}$ long, $0.90 \mathrm{~m}$ wide and $1.2 \mathrm{~m}$ in height (Figure 2). The scaled diameter of the monopole foundation tested was equivalent to $6 \mathrm{~m}$.

A paddle was located at the offshore end, and a spending beach at the inshore end of the flume. The paddle was controlled by a computer system where long crested regular wave conditions were generated by inputting wave height and period; irregular waves were generated by inputting the significant wave height and peak period assuming a JONSWAP spectrum. The duration of the regular wave simulation was such to include 300 waves in the series and the duration of the irregular wave simulation was such to include a full spectral cycle, whose duration varied according to the input period conditions.

For the purpose of the tests, the flume bottom was raised with a wooden false floor so that the floor was flushed with the side glass window to ease visualization/image capturing in the near-bed region. In the area of the cylinder the floor was a transparent Plexiglas board of $20 \mathrm{~mm}$ thickness to allow transmission of the laser beam and/or image capture.

During all tests eight resistive wave gauges were placed along the flume grouped in two sets to aid analysis and to provide information on incident and reflected wave conditions. An additional resistive wave gauge was placed in the close vicinity of the cylinder. The wave gauges were calibrated daily.

\section{EXPERIMENTAL SERIES AND SET UP}

Two series of experiments were run:

i) Common experiment. An experiment was set up to characterize the flow around a cylinder (representing an offshore wind farm mast) due to wave action. This experiment was set up in the facilities of the three institutions to be able to assess variations in the results intrinsic to the different facilities.

Using a 1:60 scale and Froude scaling criteria, the wave conditions correspond to a return period of 1 in 10 years at the Coureulles-sur-mer site. These are: significant wave height $(\mathrm{H} s)$ of $5 \mathrm{~m}$, peak period $(\mathrm{T} p)$ of $8 \mathrm{~s}$ and water depth (d) of $25 \mathrm{~m}$ and a cylinder of $6 \mathrm{~m}$ diameter.

The free surface data was collated using a method based on Goda and Suzuki (1976) formulation with four resistive wave gauges at two positions along the channel and also in the vicinity of the cylinder by an additional probe. The three components of flow velocity around the cylinder were measured with an acoustic Doppler velocimeter (ADV) at various positions and water depths in the vicinity of the cylinder.

During the experiments the ADV was mounted on a moving frame which position could be changed 

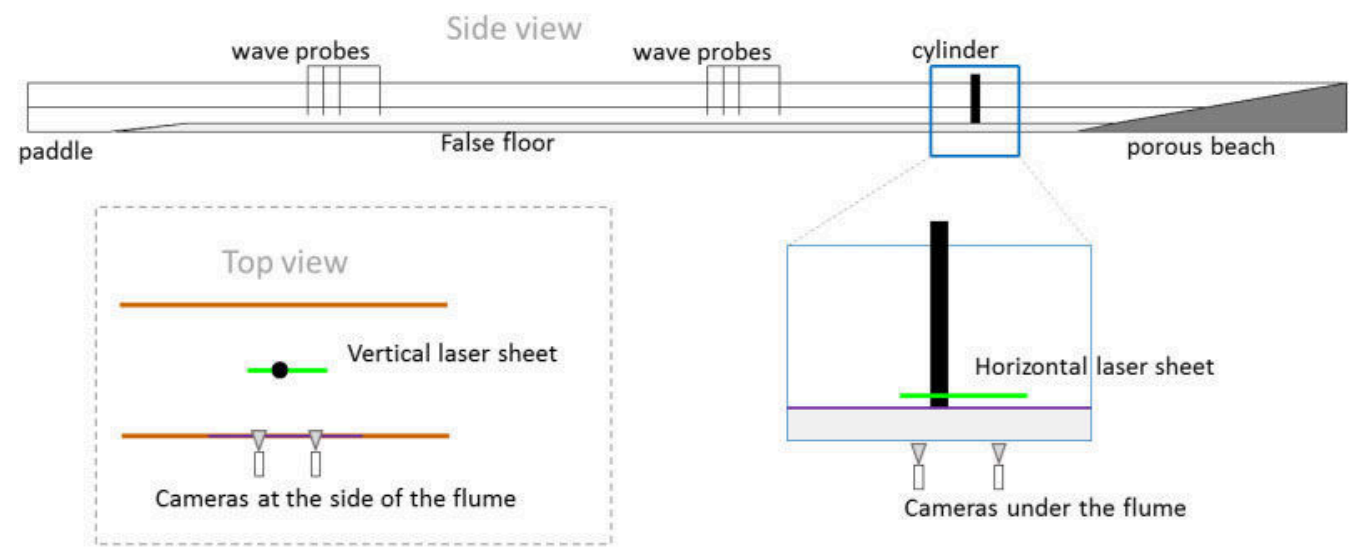

Figure 2. Layout of the flume during experiments (inset shows set-up of laser beam and cameras during PIV experiments).

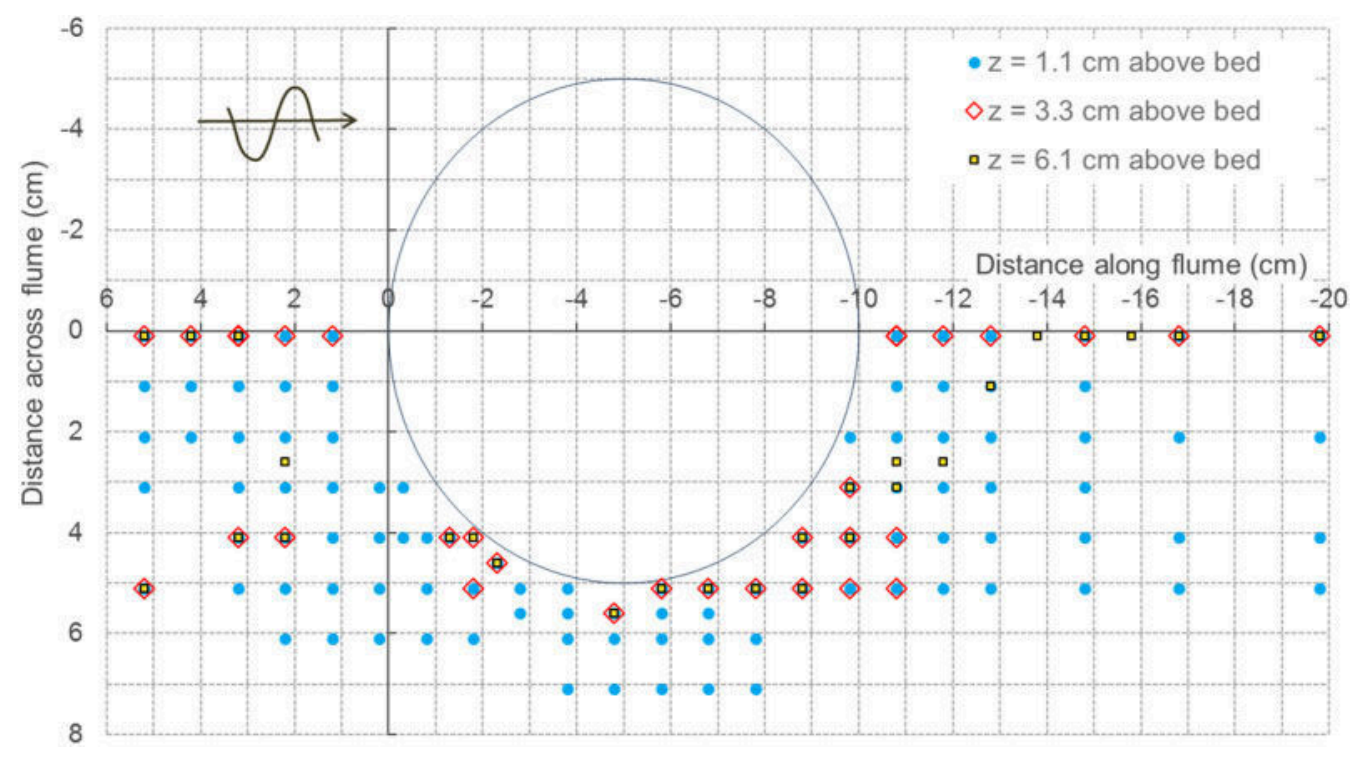

Figure 3. Location of ADV measurements of flow velocity at three depths above the bed, showing the cylinder and the incoming wave direction.

through a computer interface or directly on the machine in the across- and along-flume directions with an accuracy of $0.1 \mathrm{~mm}$.

The three components of velocity were measured at up to 100 points (Figure 3 ) at three depths above the bed (at 1.1,3.3 and $6.1 \mathrm{~cm}$ ) some measurements were repeated at a depth of $1.3 \mathrm{~cm}$ from the bed at the end of the course of experiments.

Once the ADV was positioned at the desired measurement location the free surface at the independent probe and flow velocity were recorded in a quasisynchronised manner.

ii) PIV experiments. The set of 29 experiments aimed to characterize the flow around a cylinder due to wave action, in 2D planes. The cylinder and the independent probes were set up similarly to the common experiment (Figure 2). The two components of the flow velocity were measured using PIV techniques (vertical sheet: $\mathrm{x}, \mathrm{z}$ velocity components and horizontal sheet: $\mathrm{x}, \mathrm{y}$ velocity components).

Test conditions were at scale 1:40 and 1:28 and Froude scaling criteria was used. The wave conditions (regular and irregular) and water depths for the tests are described in Table 1.

The Image capture was carried out using a system comprising a YAG pulsating laser (RDivision) synchronised with one (or two) high resolution camera and the independent free surface probe. The laser and camera(s) were arranged in a number of layouts (Figure 2) to capture information from a horizontal or vertical planes, at the upstream or downstream of the cylinder (Figures 4 and 5). 
Table 1. PIV tests conditions.

\begin{tabular}{llllll}
\hline Conditions & $\begin{array}{l}\text { Hs } \\
(\mathrm{m})\end{array}$ & $\begin{array}{l}\text { Tp } \\
(\mathrm{s})\end{array}$ & $\begin{array}{l}\text { Depth } \\
(\mathrm{m})\end{array}$ & $\begin{array}{l}\text { reg/ } \\
\text { irreg }\end{array}$ & $\begin{array}{l}\text { Scale } \\
\text { factor }\end{array}$ \\
\hline Storm 1* & 5 & 8 & 25 & $\mathrm{r} / \mathrm{i}$ & 40 \\
Storm 2 & 5 & 9 & 25 & $\mathrm{r} / \mathrm{i}$ & 40 \\
Longer period & 3 & 10 & 25 & $\mathrm{i}$ & 40 \\
KC 1 & 3 & 12 & 10.5 & $\mathrm{r}$ & 28 \\
KC 2 & 5 & 12 & 10.5 & $\mathrm{r} / \mathrm{i}$ & 28 \\
\hline
\end{tabular}

* 1:10 return period conditions at Courseulles-sur-mer.

Table 2. Non-dimensional numbers corresponding to the regular wave conditions described in Table 1.

\begin{tabular}{llllll}
\hline Conditions & $\begin{array}{l}\text { Cylinder } \\
\varnothing(\mathrm{m})\end{array}$ & $\begin{array}{l}\text { Scale } \\
\text { factor }\end{array}$ & Fr & $\begin{array}{l}\text { Re } \\
\left(10^{-6}\right)\end{array}$ & KC \\
\hline Storm 1* & 6.0 & 40 & 0.048 & 3.3 & 1.0 \\
Storm 2 & 6.0 & 40 & 0.058 & 4.1 & 1.4 \\
Longer period & 6.0 & 40 & 0.039 & 2.7 & 1.0 \\
KC 1 & 4.2 & 28 & 0.127 & 4.0 & 2.6 \\
KC 2 & 4.2 & 28 & 0.213 & 6.7 & 4.3 \\
\hline
\end{tabular}

* 1:10 return period conditions at Courseulles-sur-mer.

** KC: Keulegan Carpenter non-dimensional number.

\subsection{Test procedure}

The testing procedure during the regular and irregular waves was slightly different.

- Regular waves:

During the common experiment the paddle was started and worked for about 5 to 6 minutes, after that the recording of free surface and velocity; afterwards the ADV was moved to another measurement location and after approximately a minute the measuring started. This was repeated for the measurement points.

During the PIV experiments the paddle was started and the free surface measurements and image capture were never started within the first 5-6 minutes.

- Irregular waves:

During the PIV experiments the waves were run in spectral cycles. The paddle was started and after a full spectral cycle the acquisition and measurements started. The duration of the cycle varied with the input conditions.

\section{DATA COLLECTED AND ANALYSIS}

\subsection{Data collation}

i) Common experiment: the data capture was explained in Section 2.2

ii) PIV experiments: Conditions for the tests are shown in Table 3 . The volume of acquired data was very large and the post processing is on-going.
Table 3. Test conditions for the PIV tests.

\begin{tabular}{|c|c|c|c|c|c|c|c|}
\hline $\begin{array}{l}\text { Laser } \\
\text { sheet }\end{array}$ & $\begin{array}{l}\mathrm{Cm} \\
\text { from } \\
\text { bed }\end{array}$ & Posit & $\begin{array}{l}\text { Wave } \\
\text { (reg/ } \\
\text { irreg) }\end{array}$ & $\begin{array}{l}\text { Scale } \\
\text { factor }\end{array}$ & $\begin{array}{l}\text { Depth } \\
\text { (m) }\end{array}$ & $\begin{array}{l}\mathrm{Tp} \\
(\mathrm{s})\end{array}$ & $\begin{array}{l}\mathrm{Hs} \\
\text { (m) }\end{array}$ \\
\hline $\mathrm{v}$ & N/A & $\mathrm{D} / \mathrm{S}$ & I & 40 & 24,98 & 8 & 5 \\
\hline v & N/A & $\mathrm{D} / \mathrm{S}$ & I & 40 & 25,00 & 8 & 5 \\
\hline $\mathrm{v}$ & N/A & $\mathrm{D} / \mathrm{S}$ & I & 40 & 25,04 & 8 & 5 \\
\hline $\mathrm{v}$ & N/A & $\mathrm{D} / \mathrm{S}$ & I & 40 & 25,04 & 9 & 5 \\
\hline $\mathrm{v}$ & N/A & $\mathrm{D} / \mathrm{S}$ & I & 40 & 25,02 & 10 & 3 \\
\hline $\mathrm{v}$ & N/A & $\mathrm{D} / \mathrm{S}$ & I & 40 & 25,02 & 9 & $5 \dagger$ \\
\hline $\mathrm{v}$ & N/A & $\mathrm{D} / \mathrm{S}$ & I & 40 & 25,00 & 8 & $5 \dagger$ \\
\hline $\mathrm{v}$ & N/A & $\mathrm{D} / \mathrm{S}$ & $\mathrm{R}$ & 28 & 10,59 & 12 & 3 \\
\hline $\mathrm{v}$ & N/A & $\mathrm{D} / \mathrm{S}$ & $\mathrm{R}$ & 28 & 10,57 & 12 & 5 \\
\hline $\mathrm{v}$ & N/A & $\mathrm{D} / \mathrm{S}$ & I & 28 & 10,57 & 12 & 5 \\
\hline v & N/A & $\mathrm{D} / \mathrm{S}$ & I & 40 & 25,06 & 8 & $5 ¥$ \\
\hline $\mathrm{v}$ & N/A & $\mathrm{U} / \mathrm{S}$ & I & 40 & 25,04 & 8 & $5 ¥$ \\
\hline $\mathrm{v}$ & N/A & $\mathrm{U} / \mathrm{S}$ & I & 40 & 25,04 & 8 & 5 \\
\hline $\mathrm{v}$ & N/A & $\mathrm{U} / \mathrm{S}$ & I & 40 & 25,04 & 9 & 5 \\
\hline $\mathrm{v}$ & N/A & $\mathrm{U} / \mathrm{S}$ & I & 40 & 25,04 & 10 & 3 \\
\hline $\mathrm{v}$ & N/A & $\mathrm{U} / \mathrm{S}$ & $\mathrm{R}$ & 28 & 10,63 & 12 & 3 \\
\hline $\mathrm{v}$ & N/A & $\mathrm{U} / \mathrm{S}$ & $\mathrm{R}$ & 28 & 10,63 & 12 & 5 \\
\hline $\mathrm{v}$ & N/A & $\mathrm{U} / \mathrm{S}$ & I & 28 & 10,63 & 12 & 5 \\
\hline $\mathrm{h}$ & 3.0 & $\mathrm{D} / \mathrm{S}$ & I & 40 & 24,98 & 8 & 5 \\
\hline h & 2.5 & $\mathrm{D} / \mathrm{S}$ & I & 40 & 24,98 & 8 & 5 \\
\hline $\mathrm{h}$ & 1.4 & $\mathrm{D} / \mathrm{S}$ & I & 40 & 24,94 & 8 & 5 \\
\hline $\mathrm{h}$ & 7.5 & $\mathrm{D} / \mathrm{S}$ & I & 40 & 24,94 & 8 & 5 \\
\hline $\mathrm{h}$ & 3.2 & $\mathrm{U} / \mathrm{S}$ & $\mathrm{R}$ & 40 & 10,58 & 12 & 3 \\
\hline $\mathrm{h}$ & 3.2 & $\mathrm{U} / \mathrm{S}$ & $\mathrm{R}$ & 40 & 10,54 & 12 & 5 \\
\hline $\mathrm{h}$ & 3.2 & $\mathrm{U} / \mathrm{S}$ & I & 40 & 24,94 & 8 & 5 \\
\hline $\mathrm{h}$ & 1.4 & $\mathrm{U} / \mathrm{S}$ & I & 40 & 24,94 & 8 & 5 \\
\hline $\mathrm{h}$ & 7.5 & $\mathrm{U} / \mathrm{S}$ & I & 40 & 24,94 & 8 & 5 \\
\hline $\mathrm{h}$ & 7.5 & SIDE & I & 40 & 24,94 & 8 & 5 \\
\hline $\mathrm{h}$ & 1.4 & SIDE & I & 40 & 24,94 & 8 & 5 \\
\hline
\end{tabular}

$\mathrm{H}$ : horizontal laser sheet; v: vertical laser sheet $\dagger$ †oom; ¥ larger zoom; R: regular; I: irregular U/S: upstream; D/S: downstream

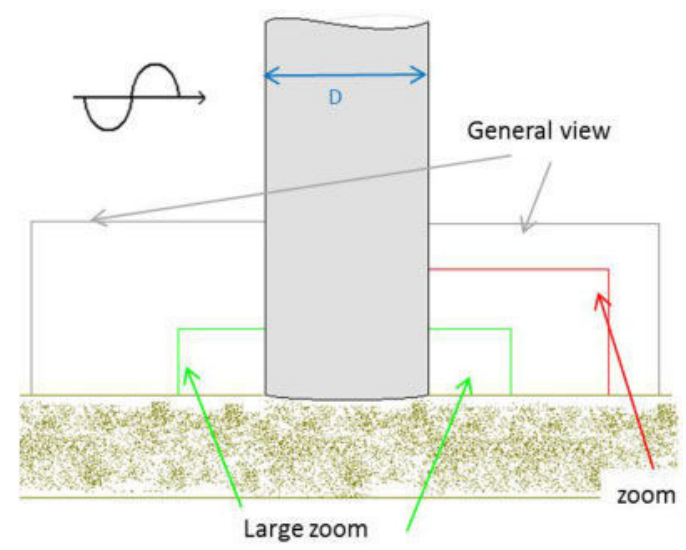

Figure 4. Location of vertical laser sheet around the cylinder.

The two main test set ups were:

(a) vertical laser sheet (Figure 4) across the centerline of the cylinder, upstream and/or downstream; where the laser sheet was projected from the 


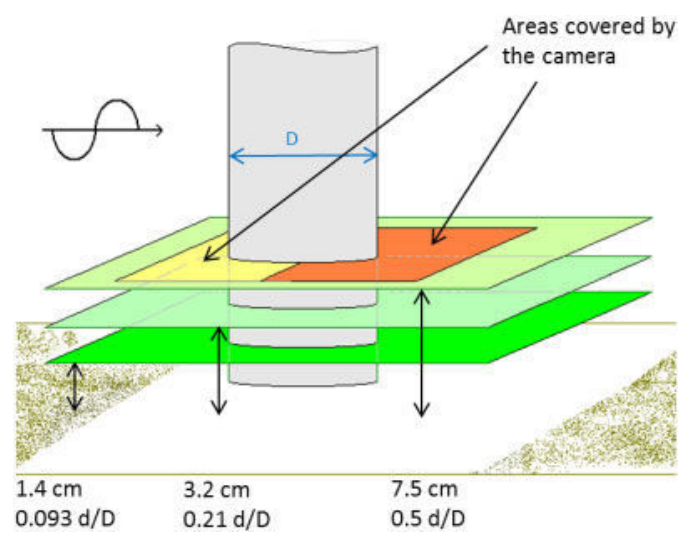

Figure 5. Location of horizontal laser sheet with respect to the cylinder.

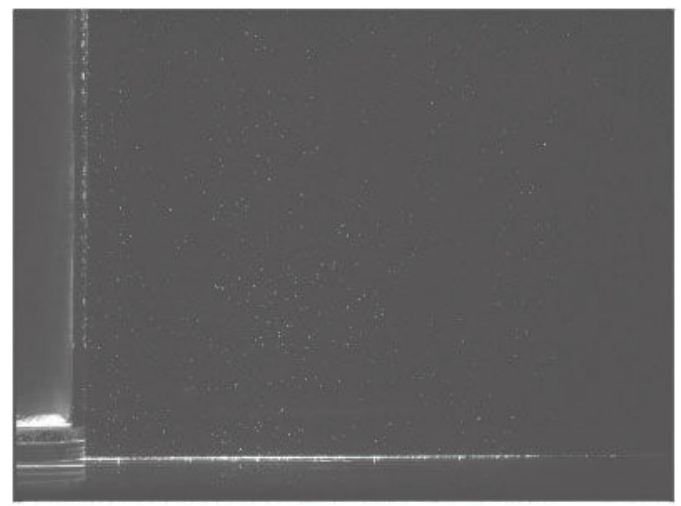

Figure 6. Image showing the field of view of the near field downstream of the cylinder.

bottom of the channel through a glass window and the Plexiglas floor, the camera (s) was (were) located at the side of the flume and capture images through a glass window; and

(b) horizontal laser sheet (Figure 5) at a distance from the false bed upstream or downstream from the cylinder, where the laser sheet was projected from the side of the channel through a glass window, the camera (s) was (were) located at the bottom of the flume and capture images through a glass window and the Plexiglas floor.

\subsection{Data analysis}

Both datasets from the common and PIV experiments required an intensive program for post processing.

i) Common experiment data: The ADV data required to be cleaned by using the method developed by Goring and Nikora (2002) and modified by Mori et al (2007). The free surface data needed to be resynchronised with the velocity measurements due to a short time lag between the start of the free surface measurement and the ADV.
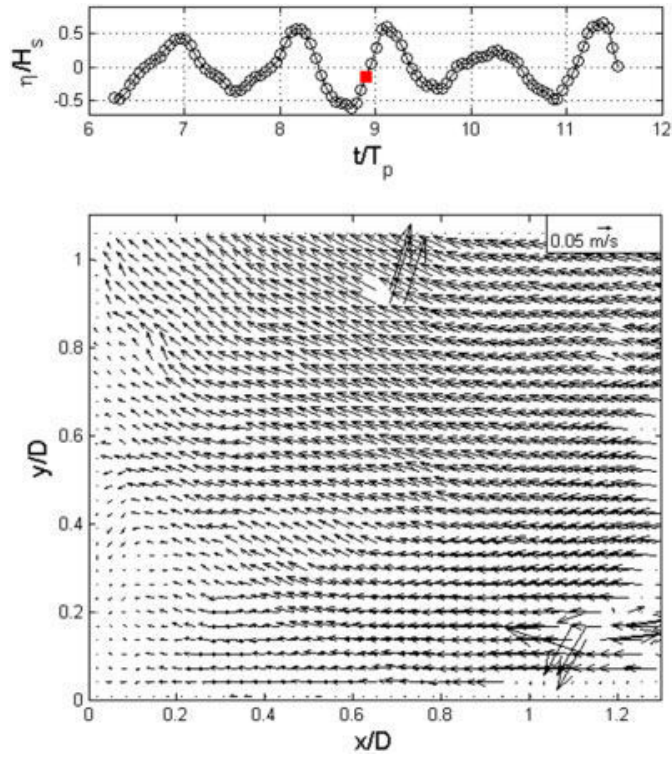

Figure 7. Vector field downstream of the cylinder with top inset showing the corresponding instant for the free surface.

ii) PIV experimental data: The data processing followed three stages of post processing. Conversion from digital image (Figure 6) to particle displacement, calibration of displacement to obtain velocity vectors (Figure 7) and the application of global, local and interpolation filters that removes spurious vectors.

Other post processing steps that can be used are the subtraction of the mean image to each image in a previous step to the calculation of the displacement, to improve contrast within the image between the background and the particle; or applying a mask to blank out areas of the image that are of no interest.

\section{PRELIMINARY FINDINGS}

The discussion of findings includes only the very preliminary results from the PIV experimental data. Currently the analysis phase is on-going.

From the initial stages of the analysis a series of flow structures (vortices, jets and other recirculation patterns) have been identified up- and downstream from the cylinder either through video analysis directly from the acquired images or vector images resulting from initial PIV post processing.

In Figure 8 the top inset shows the state of the free surface at the side of the cylinder at the corresponding instant of the vector field. The bottom inset shows the vector flow field immediately downstream of the cylinder along the centerline of the flume. The back of the cylinder corresponds to the left axis, and the flume floor corresponds to the bottom axis. Despite the $\mathrm{KC}$ number for the test being smaller than 4 (which is considered the threshold value for the presence of 

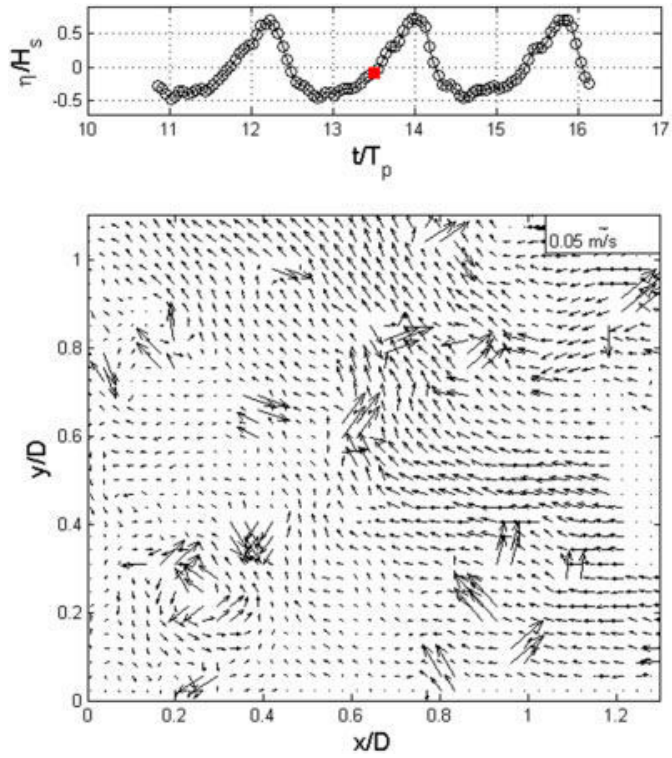

Figure 8. Velocity field downstream of the cylinder. A vortex is observed at the bottom left of the figure. The top inset shows the state of the free surface.

vortex shedding in Sumer et al (1997)) a vertical vortex was visible near the bed during a regular wave test as the next wave approached the cylinder. A number of spuriously large vectors are also shown in this image. Further post processing is required to remove these vectors.

Figure 9 ( $a, b$ and $c)$ shows the evolution of the flow field downstream of the cylinder, with irregular wave conditions, as the wave approaches the cylinder. Several recirculation structures are present in the sequence as well as a couple of patches of spurious vectors that need to be filtered out.

\section{CONCLUSIONS}

The present results are preliminary findings and further post-processing and quantitative analysis will provide a deeper insight into the flow velocity increases in the vicinity of the cylinder and near the bed and these in turn will provide estimates of increases in bed shear stresses due to waves only.

Flow structures such as vortices and other recirculation patterns near bed were observed upstream as the wave propagates around the cylinder. Observed flow recirculation patterns up- and downstream of the cylinder may increase the stirring effect of the waves on the bed and have an influence on the sediment erosion and deposition patterns in the area, in the short and long term.

The analysis of flow vector fields under regular and irregular waves highlighted that unlike in the regular wave case where flow patterns are repeated with each wave, with irregular waves the flow patterns are characteristics to the particular passing wave
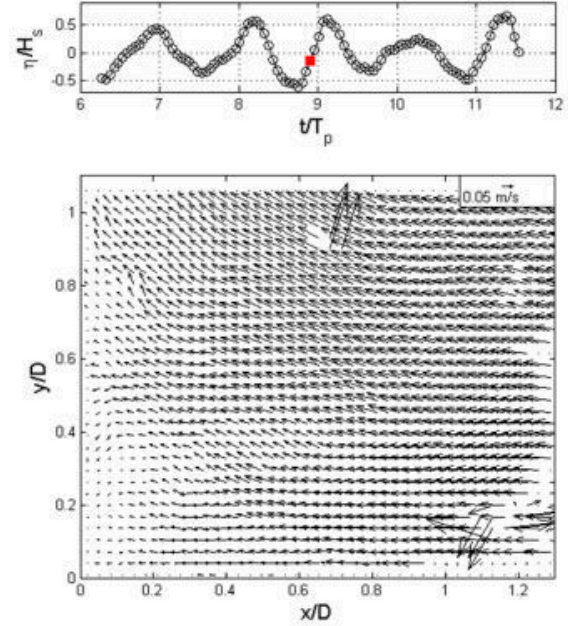

a)
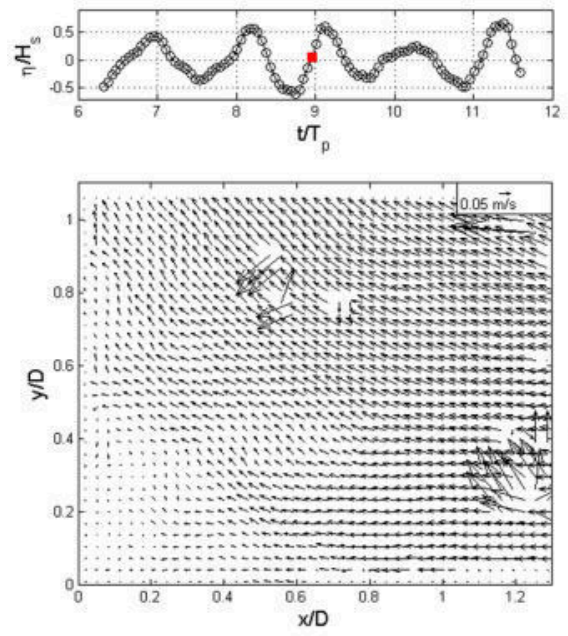

b)
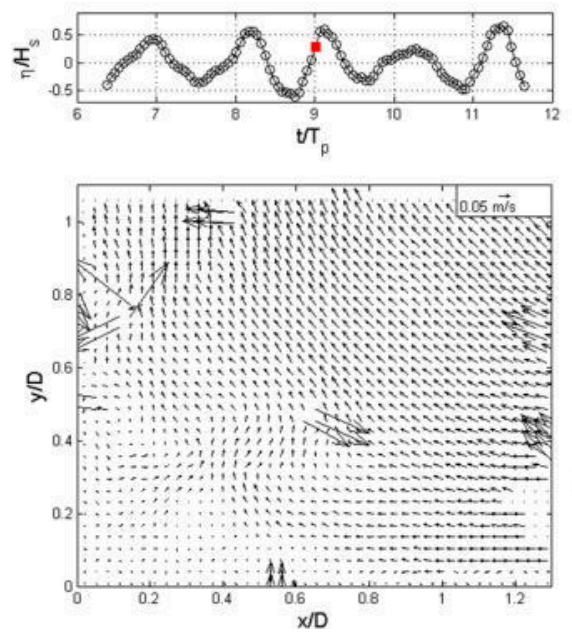

c)

Figure 9. Sequence of flow fields downstream of the cylinder as the wave passes through (irregular wave conditions). Top inset shows the free surface. 
but highly dependent on the 'wave-history' i.e. on the characteristics of the previous wave.

The experiments and results presented in this paper are due only to wave forcing. The present study is embedded into OFELIA which has a wider scope to include experiments comprising currents and sediment transport.

It is the aim of the project to put together the findings from parallel experimentation and numerical modeling to improve understanding of the hydrodynamic and sedimentary processes around a cylinder.

\section{REFERENCES}

Department of Energy and Climate Change. (2013). Annual tables: 'Digest of UK energy statistics' (DUKES) Chapter 6: Renewable Sources of energy. Retrieved 1 September 2013.

Goda, Y., and Suzuki, Y. (1976). . Suzuki, 1976. Estimation of incident and reflected waves in random wave experiments. Proceedings of the 15th International Conference. Coast Eng, (ICCE'76), ASCE, Honolulu, Hawaii, pp. 828-845.

Lam, K. M., Hu, J. C., Liu, P. (2010). Vortex formation processes from an oscillating circular cylinder at High Keulegan-Carpenter numbers. Phys. Fluids. (22), 015105.

Mori N., Suzuki, T., Kakuno, S. (2007). Noise of acoustic Doppler velocimeter data in bubbly flows. J. Eng. Mech., January 2007, pp. 122-125.
Nikora, V. I., Goring, D. G. (2002). Despiking acoustic Doppler velocimeter data. J. Hydraul. Eng., January 2002, pp. 117-126.

Ozgoren, M., and Rockwell, D. (2007). Interaction of a deepwater wave with a vertical cylinder: effect of self-excited vibrations on quantitative flow patterns. J. Fluid Mech. (572) pp. 189-217.

Sumer, B.M., Christiansen, N., Fredsoe, J. (1997). Horseshoe vortex and vortex shedding around a vertical wallmounted cylinder exposed to waves. J. Fluid Mech. 332, 41-70.

Sumer, B. M., Whitehouse, R. J. S., Torum, A. (2001). Scour around coastal structures: a summary of recent research. Coastal. Eng. (44), pp. 153-190.

Syndicat Syndicat des Energies Renouvelables. (2014). Energies Marines: quelles perspectives de création de valeur en France? Avril 2014. (http://www.enr.fr/docs/ 2014102616_EYCCASSEnergiesmarines.pdf)

Yang, Y., and Rockwell, D. (2002). Wave interaction with a vertical cylinder: spanwise flow patterns and loading. J. Fluid Mech. (460), pp. 93-129.

Zanke, U.C.E., Hsu, T.W., Roland, A., Oscar, L., Reda, D. (2011). Equilibrium scour depths around piles in noncohesive sediments under currents and waves. Coast. Eng. 58, pp. 986-991. 